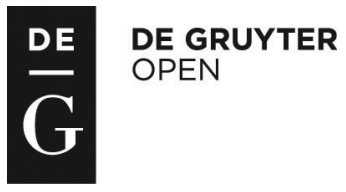

\title{
EFFECT OF UTERINE INFLAMMATORY STATUS AS WELL AS CALCIUM AND MAGNESIUM CONCENTRATIONS ON THE UTERINE INVOLUTION PROCESS IN DAIRY COWS*
}

\author{
Piotr Brodzki ${ }^{1 \bullet}$, Adam Brodzki², ${ }^{2}$ ukasz Kurek ${ }^{3}$, Maria Szpetnar ${ }^{4}$, Mariola Bochniarz ${ }^{1}$ \\ ${ }^{1}$ Department and Clinic of Animal Reproduction, \\ ${ }^{2}$ Department and Clinic of Animal Surgery, \\ ${ }^{3}$ Department and Clinic of Internal Medicine, \\ University of Life Sciences in Lublin, Głęboka 30, 20-612 Lublin, Poland \\ ${ }^{4}$ Department of General Chemistry, Medical University in Lublin, 20-093 Lublin, Poland \\ •Corresponding author: Piotr Brodzki: wetdoc@interia.pl
}

\begin{abstract}
The aim of the study was a comparative analysis of uterine horn diameter, calcium and magnesium concentrations in blood serum and uterine washings in cows both with and without endometritis. The study was performed on 28 cows at 5, 22 and 42 DPP (day post partum), of which 14 cows had been diagnosed with endometritis and the other 14 had no endometritis. The animals were selected based on clinical symptoms and cytological examination. Uterine horn diameter was determined in both examined groups of cows using an ultrasonographic device. The level of calcium and magnesium in the blood serum and uterine washings, and protein in uterine washings was determined using a BS-160 Mindray analyzer. Uterus diameter was similar in both examined groups of cows only at 5 DPP, and on subsequent days of examination this parameter was higher in the endometritis group compared to the control $(\mathrm{P}<0.001)$. Calcium levels in the blood serum of cows with endometritis were lower than in cows without endometritis, both at $22 \mathrm{DPP}(\mathrm{P}<0.001)$ and at 42 DPP $(\mathrm{P}=\mathbf{0 . 0 0 4})$. The levels of calcium, magnesium and total proteins in uterine washings were higher in cows with endometritis compared to the group without endometritis, both at 22 and at $42 \mathrm{DPP}(\mathrm{P}<\mathbf{0 . 0 0 1})$. The results of this study confirm that the process of uterine involution is slower in cows with endometritis compared to cows without endometritis, and the myometrium of inflamed uterus does not utilize sufficient amounts of calcium and magnesium, which means that the concentrations of these elements in uterine fluid are higher than in cows without endometritis.
\end{abstract}

Key words: calcium, endometritis, magnesium, total proteins, uterine involution

Inflammation of the uterus constitutes a serious problem in dairy cow breeding all over the world, and it may lead to significant economic losses related mainly to cow fertility disorders (Potter et al., 2010; Gilbert, 2011; Galvão, 2012). Microorgan-

\footnotetext{
*This study was funded by internal research funds of the Department and Clinic of Animal Reproduction, Faculty of Veterinary Medicine of the University of Life Sciences in Lublin.
} 
isms proliferating in the uterine cavity and endometrium may cause uterine inflammation (Földi et al., 2006; Bicalho et al., 2010; Gautam et al., 2010).

Post partum uterine involution in cows lasts for quite a long time and may be divided into two stages. The first stage, when the uterus returns to its size from the pre-pregnancy period, lasts from 21 to 25 days after parturition and is called the post partum period. The so-called clinical post partum period ends at this time. The second stage involves histological recovery of the uterus to the condition before the pregnancy, and ends with complete uterine involution, and may last up to six weeks or, according to Sheldon et al. (2008), even up to 8 weeks after parturition.

The process of uterine involution depends on numerous factors and disorders, which predispose the uterus to inflammations. Partus gravis, twin pregnancy, a dead fetus or a retained placenta may cause uterine atony or hypotonia (LeBlanc et al., 2002; Bell and Roberts, 2007). There may be also an effect of systemic disorders such as a negative energy balance or mineral-vitamin deficiencies (Goff, 2008; Wathes, 2012). Stress reactions with stress mediator formation, especially corticosteroids and adrenalin, are the result of deficiencies intensified after parturition. Catecholamines, which affect $\beta$-adrenergic receptors, cause uterine atony or hypotonia. An excess of corticosteroids inhibits immune system and also has a significant effect on retained placenta and development of uterine infections (Goff, 2008; Sheldon et al., 2008).

Myofiber contraction and the activation of actin-myosin arrangement depend directly on calcium ion presence. In turn, magnesium ion presence is essential both for calcium accumulation in myocytes, especially in endoplasmic reticulum, as well as in active cellulipetal calcium transport. These processes occur using energy stored in adenosine-5'-triphosphate (ATP), and by degradation of high-energy bonds. Further energy utilization depends on the presence of magnesium ions (Marshall, 1962; Parkington and Coleman, 2001). A properly functioning uterine myometrium makes use of both calcium and magnesium in the contraction process. It is not known, however, whether these elements are used in the same manner in an inflamed uterus. Uterine inflammation, especially in the post partum period, may inhibit uterine involution to a considerable degree (Kasimanickam et al., 2004). It is not known, however, which mechanisms occurring during uterine inflammatory states may disturb its contractility and involution. The parameter which is frequently taken into account in cow examinations, especially in the post partum period, is the determination of uterine horn or cervix diameter in various post partum periods in order to analyze uterine involution dynamics (Čengić et al., 2012; Leurent et al., 2013).

The aim of this study was a comparative analysis of post partum uterine involution based on uterine horn diameter measurements. The analysis was performed on cows with endometritis and on cows free of uterine inflammation using ultrasonography. In addition, the study aimed to determine intrauterine and serum calcium and magnesium concentrations in both mentioned groups of cows, so that these concentrations could be used as indices of uterus contraction activity. 


\section{Material and methods}

The study was approved by the Local Ethics Committee at the University of Life Sciences in Lublin. The study was conducted on 28 cows of Holstein-Friesian (HF) breed aged from 3 to 6 years, after second or third parturition. The animals were maintained in the same environmental conditions, and were fed and housed in the same way. The feeding was based on the Total Mixed Ration (TMR) system including maize silage, grass silage, straw, ground grain, soybean meal with proteins and minerals. The condition of the cows was assessed as being good or very good (Body Condition Score 3.5-4.0), and in the previous lactation the cows had produced over 7500 liters of milk.

All cows that calved in the period from February to October 2012 (58 animals) were subjected to routine veterinary control in the post partum period. Apart from a general animal examination, the control included detailed examination of the reproduction system, based on vaginoscopic examination, rectal uterus examination performed with a Honda HS-1500 ultrasonography machine (Honda Electronics Co., Ltd., Toyohashi, Japan), with a dual frequency $5.0 / 7.5 \mathrm{MHz}$ intrarectal transducer, and uterus cytology. Uterine horn diameter in the examined cows was also determined using the ultrasound apparatus in order to analyze the dynamics of uterine involution in specified post partum periods.

The above examinations were performed for the first time at 5 days post partum (DPP). Based on them it was established that inflammation (clinical metritis) occurred in part of the examined cows ( 25 animals). The condition was manifested as brown or brown-bloody discharge of characteristic unpleasant smell, from the reproductive tract, and the uterus was considerably enlarged. Retained placenta or puerperal metritis with general disease symptoms were observed in 6 cows, and these animals were subjected to appropriate treatment and excluded from the experiment. In the other cows in the herd (27 animals) at 5 DPP only brown-bloody-mucous fluid without unpleasant smell and enlarged uterus characteristic of the early postpartum period was observed.

The second examination was performed at 22 day post partum and enabled the selection of 14 cows from the whole herd which still presented inflammation of the uterus (clinical endometritis) and had either a pus/mucus-like discharge from the reproduction tract or visible on vaginoscopic examination. The inflammation was additionally confirmed via cytological examination (neutrophil count above 18\%), according to Sheldon et al. (2006). These cows constituted the experimental group. Fourteen cows were also selected from the remaining animals, i.e. without clinical endometritis symptoms and without uterine inflammatory state determined via cytological examination (neutrophil count below 18\%) and constituted the control group. None of the animals from either group exhibited general health status disorders (metabolic diseases, udder inflammations, abomasum displacement, etc.), which would affect the obtained results.

The examinations were performed again at 42 day post partum on the animals selected for the experiment. At this time, the flush from the reproduction tract or pus/ mucus-like secretion visible on vaginoscopic examination were still maintained in 
the cows from the experimental group, and the neutrophil count in cytological examination was above $10 \%$. Despite having clinical endometritis the cows from the experimental group were not subjected to treatment, since such a procedure would affect the results. Appropriate treatment was given after the end of the study. The dates of examinations and threshold values of neutrophils in cytological examination after the post partum period (after the 21 st day post partum) were determined at times consistent with the rules accepted by Kasimanickam et al. (2004) and Sheldon et al. (2006). Uterus cytology was performed using a cytology brush (Jiangsu Yada Technology Group Co., Ltd, Jiangsu, China) adapted for cows. The procedure of material collection for cytological examination was conducted according to the literature methods (Kasimanickam et al., 2004; Sheldon et al., 2006). Cytological smears were performed directly from the brushes as imprint samples on the microscope slide. Slides for cytological examination were prepared by rolling the uterobrush onto a clean microscope glass slide. After drying, the samples were fixed and stained using Hemacolor staining (Merck KGaA, Darmstadt, Germany). Then, the specimens were analyzed using an Olympus CX 41 microscope (Olympus Corporation, Tokyo, Japan), at 400x magnification. Cytological examination of the specimens was based on an evaluation of neutrophil count in the smears. At least 100 cells (endometrial cells, leukocytes) visible in various fields of view in particular samples were counted and the percentage of neutrophils was assessed.

Uterine washings and blood were the material for the main examinations; calcium and magnesium levels as well as protein concentrations in uterine washings were evaluated at 5, 22 and 42 days post partum. The washings were collected according to the literature (Kasimanickam et al., 2004; Sheldon et al., 2006) and centrifuged at $1000 \times \mathrm{g}$ for $10 \mathrm{~min}$. The supernatant was collected for the examinations and the precipitate was removed. Nine $\mathrm{ml}$ of blood for examinations was collected into test tubes from the external jugular vein using a Vacutest coagulation activator (Vacutest Kima srl, Arzergrande (PD), Italy). Total magnesium concentrations in blood and washings were determined using an Accent-200 Mg set (Cormay S.A., Łomianki, Poland). Total calcium in blood and washings was examined based on an Accent-200 Calcium diagnostic set (Cormay S.A., Lomianki, Poland), while total protein content in washings was evaluated using an Accent-200 Total Protein kit (Cormay S.A., Łomianki, Poland). The examinations were performed using a BS-160 analyzer (Mindray Medical International Limited, Shenzhen, China).

\section{Statistical analysis}

The Shapiro-Wilk test was used in order to confirm the normal distribution of the examined features. The results obtained were compared between the groups in order to determine their statistical significance using the Student's t-test. P-value $<0.05$ was considered statistically significant. Statistical differences between the results from the material collected at different times in the two groups were calculated using post-hoc Tukey's and Duncan's tests, for a probability value of $\mathrm{P}<0.01$. 


\section{Results}

The results of cytological examinations were demonstrated in Figure 1. The neutrophil percentage was subject to a decrease in both groups in the subsequent examinations. However, in the experimental group it was higher $(\mathrm{P}<0.001)$ compared to the control group, both at 22 and at 42 DPP.

\section{Cytological examination}

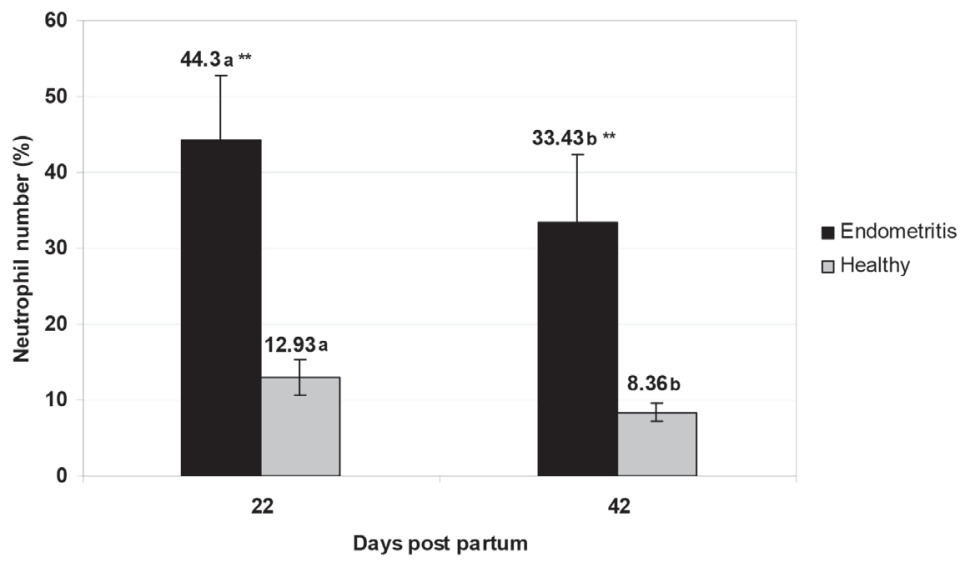

Figure 1. Results of cytological examination of the uterus in cows with (Endometritis) and without endometritis (Healthy). ${ }^{* *}$ - statistically significant differences at $\mathrm{P}<0.001$ between endometritis and healthy cows. $\mathrm{a}-\mathrm{b}-$ statistical differences between the results for the material collected at different times in the group, for probability $\mathrm{P}<0.01$

\section{Measurements of the uterus}

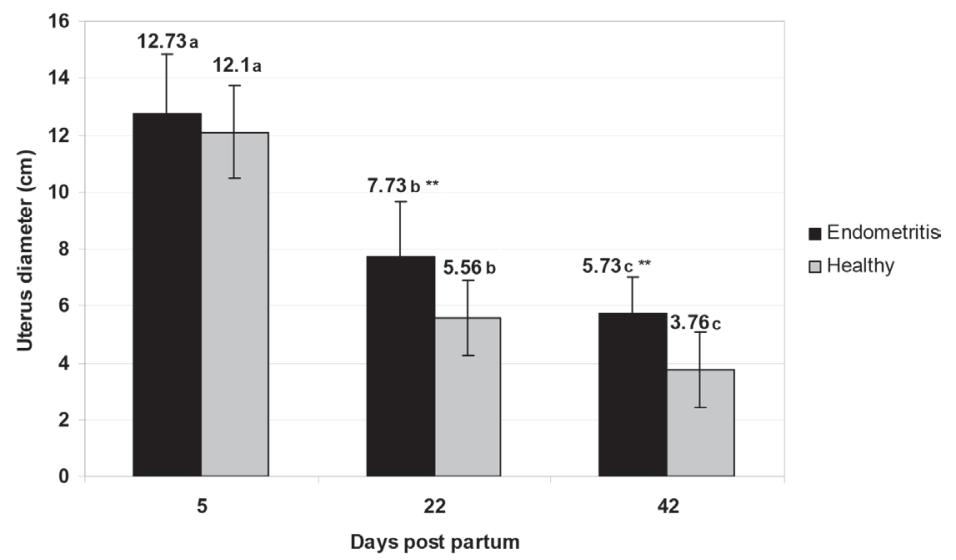

Figure 2. Results of measurements of the uterus (uterine diameter) in cows with (Endometritis) and without endometritis (Healthy). ${ }^{* *}$ - statistically significant differences at $\mathrm{P}<0.001$ between endometritis and healthy cows. a-c - statistical differences between the results for the material collected at different times in the group, for probability $\mathrm{P}<0.01$ 
Table 1. The results of the examinations performed at 5, 22 and 42 days post partum (DPP), both in cows with endometritis and in cows without endometritis (Healthy) $(n=28)$

\begin{tabular}{l|c|c|c|c|c|c}
\hline \multirow{2}{*}{ Examined parameters } & \multicolumn{3}{c|}{ Endometritis $(\mathrm{n}=14)$} & \multicolumn{3}{c}{ Healthy $(\mathrm{n}=14)$} \\
\cline { 2 - 7 } & $5 \mathrm{DPP}$ & $22 \mathrm{DPP}$ & $42 \mathrm{DPP}$ & $5 \mathrm{DPP}$ & $22 \mathrm{DPP}$ & $42 \mathrm{DPP}$ \\
\hline Calcium level, washings (mmol/L) & $0.613 \mathrm{a}$ & $0.921 \mathrm{~b}^{* *}$ & $0.374 \mathrm{c}^{* *}$ & $0.589 \mathrm{a}$ & $0.204 \mathrm{~b}$ & $0.166 \mathrm{c}$ \\
& \pm 0.200 & \pm 0.149 & \pm 0.083 & \pm 0.195 & \pm 0.008 & \pm 0.018 \\
Calcium level, serum (mmol/L) & $1.897 \mathrm{a}$ & $1.667 \mathrm{~b}^{* *}$ & $1.985 \mathrm{a}^{*}$ & $1.921 \mathrm{a}$ & $2.122 \mathrm{~b}$ & $2.213 \mathrm{~b}$ \\
& \pm 0.117 & \pm 0.262 & \pm 0.224 & \pm 0.123 & \pm 0.513 & \pm 0.424 \\
Magnesium level, washings & $0.264 \mathrm{a}$ & $0.218 \mathrm{a} *$ & $0.162 \mathrm{~b} *$ & $0.258 \mathrm{a}$ & $0.093 \mathrm{~b}$ & $0.085 \mathrm{~b}$ \\
(mmol/L) & \pm 0.062 & \pm 0.084 & \pm 0.064 & \pm 0.082 & \pm 0.022 & \pm 0.021 \\
Magnesium level, serum (mmol/L) & $0.915 \mathrm{a}$ & $0.828 \mathrm{a}$ & $0.864 \mathrm{a}$ & $0.987 \mathrm{a}$ & $1.013 \mathrm{a}$ & $1.045 \mathrm{a}$ \\
& \pm 0.233 & \pm 0.272 & \pm 0.085 & \pm 0.261 & \pm 0.228 & \pm 0.234 \\
Protein level, washings (mg/L) & $1.72 \mathrm{a}$ & $1.69 \mathrm{a} * *$ & $1.60 \mathrm{a} * *$ & $1.61 \mathrm{a}$ & $0.93 \mathrm{~b}$ & $0.54 \mathrm{c}$ \\
& \pm 0.29 & \pm 0.28 & \pm 0.71 & \pm 0.15 & \pm 0.73 & \pm 0.29 \\
\hline
\end{tabular}

mean \pm SEM, statistically significant differences $*$ - at $\mathrm{P}<0.01$ and $* *-\mathrm{P}<0.001$ between endometritis and healthy cows.

a-c statistical differences between the results for the material collected at different times in the group, for probability $\mathrm{P}<0.01$.

Uterus diameter was similar in both examined groups of cows only at $5 \mathrm{DPP}$, and in subsequent examinations it was distinctly and statistically higher in the experimental group compared to the control group $(\mathrm{P}<0.001)$. The uterine diameter was subject to a decrease in the next examinations in both groups (Figure 2).

Calcium levels in blood serum of cows with endometritis were the lowest at 22 DPP, and this was also a value which was statistically lower compared to the values obtained in the group of cows without endometritis $(\mathrm{P}<0.001)$. In the last examination at 42 DPP, the calcium level values obtained in the experimental group were also statistically lower than those in the control group $(\mathrm{P}=0.004)$. In turn, calcium levels in uterine washings were higher in cows with endometritis compared to cows without endometritis, both at $22 \mathrm{DPP}(\mathrm{P}<0.001)$ and at $42 \mathrm{DPP}(\mathrm{P}<0.001)$ (Table 1).

The level of magnesium in the blood serum of cows in the experimental group was lower than in the control group. Magnesium levels in uterine washings were similar in both examined groups of animals only at 5 DPP, and in subsequent examinations the parameter was higher in the group of cows with endometritis than in cows without endometritis, both at $22 \mathrm{DPP}(\mathrm{P}<0.001)$ and at $42 \mathrm{DPP}(\mathrm{P}<0.001)$. In the experimental group the magnesium level in the uterine washings was lower in the 42 DPP compared to the previous studies $(\mathrm{P}<0.01)$. In the control group the magnesium level in the uterine washings was lower on days 22 and 42, compared to day 5 (Table 1 ).

The total protein levels in uterine washings at 22 and 42 DPP were also higher in cows with endometritis compared to the cows without uterine inflammatory state $(\mathrm{P}<0.001)$. In the experimental group protein levels were similar on all evaluation dates, while in the control group at day 42 they were statistically lower than at 5 and 22 DPP $(\mathrm{P}<0.01)$ (Table 1). 


\section{Discussion}

The uterus in cows after parturition is considerably enlarged, and inflammation is usually observed, which may intensify or be eliminated (LeBlanc et al., 2002; Sheldon et al., 2006). It is proved by a similar uterus diameter measured at 5 day post partum, when physiological post partum uterus enlargement is observed practically in all cows. According to literature data, post partum inflammation of uterus without systemic symptoms is observed in $35-50 \%$ of cows, i.e. among all animals calving in dairy cow herds (Sheldon et al., 2009 a).

Inflammation occurring just after parturition is quickly eliminated during the proper course of the post partum period, and the uterus systematically returns to its size from the period before pregnancy. In some cows, inflammation may, however, be observed long after parturition and may delay uterine involution (Kasimanickam et al., 2004; Sheldon et al., 2009 b). Such relationship was also observed in the current study. Maintained endometritis distinctly and negatively affected the process of uterine contraction. In cows with endometritis, uterus diameter, both at 22 and at 42 DPP, was significantly higher compared to cows without inflammation which were in the same phase of the post partum period. Apart from clinical symptoms (secretions) and increased neutrophil count observed in cytology, confirmation of maintained uterine inflammatory condition was also proved by an increased total protein level, which was observed in this study in the uterus of cows with endometritis. An increased protein level in uterine washings is a result of increased permeability of the blood and lymphatic vessels supplying the uterus, which is a result of released inflammatory mediators created by phagocytic cells (neutrophils, macrophages, monocytes), mast cells and endometrial cells (Sabounchi-Schutt et al., 2003; Wattiez and Falmagne, 2005). This is a reaction to pathogens present in cow's uterus in the post partum period. These mediators mainly include cytokines such as Tumor Necrosis Factor $\alpha(\mathrm{TNF} \alpha)$ and interleukins (IL) 1, 6, 8, which have an ability to dilate blood vessels, while IL-1 additionally elevates blood calcium levels in the post partum period, which is essential for proper uterine involution (Singh et al., 2008).

Blood vessel dilatation increases the inflow of numerous components to the uterus, including immunologically competent cells participating in the elimination of inflammation, as well as energetic substances and elements directly contributing to uterine involution. This study confirms the increased inflow of elements to the uterus, since significantly higher concentrations of both calcium and magnesium were observed in uterine washings in cows with endometritis compared to the cows without inflammation. During the period in which cytokines are active according to the literature data, the concentrations of the mentioned elements in uterus are higher during inflammatory process compared to the period when inflammation was not observed (Singh et al., 2008). These elements are essential in myofiber contraction and proper uterine involution processes. However, it is also known from numerous publications that uterine involution is considerably weakened in cows with confirmed metritis and endometritis (Kasimanickam et al., 2004; Sheldon et al., 2006). Disturbances in the process of uterus self-cleaning, especially in the post partum period, to a considerable degree facilitate the formation and maintenance of infections (Shel- 
don et al., 2006, 2008). Current study concerning uterus diameter measurements confirms that uterine involution in cows with endometritis was considerably lower compared to cows without endometritis, and that greater uterus diameter was associated with an increase in neutrophil content in cytological examination, and with increased calcium and magnesium levels in uterine lavage. Thus, uterine involution is weakened during inflammatory states, despite increased calcium and magnesium levels inside the uterus.

According to the authors, only inflammatory state observed after parturition may positively affect uterus contraction, when dilated vessels increase uterus blood flow and provide higher amounts of products used in the mechanism of myofiber contraction and accelerate uterine involution. This was observed in cows with a proper post partum period, quickly eliminating uterine inflammatory state. In cows in which inflammatory process is maintained long after parturition, these elements are not utilized by myometrium in sufficient amounts despite their proper inflow, and are transferred to the uterine cavity, from which they presumably cannot be absorbed. Other study demonstrated that in the case of an enhanced potential for uterine myometrium contraction, which is observed for example in cows during estrus, calcium and magnesium levels in uterine fluid are significantly lower compared to the corpus luteum phase, when myometrium does not demonstrate any movement activity (Hugentobler et al., 2007). This confirms the fact that elements provided to the uterus are used by a properly functioning myometrium, and only small amounts of these elements reach the uterine cavity. However, in the case of lowered uterus contractility, these elements are captured in the myometrium in lower amounts, and the majority of them is transferred to the uterus cavity (Hugentobler et al., 2007). Such mechanism is presumably also observed during uterine inflammatory states, when calcium and magnesium levels in uterine secretion are increased as a result of myometrium functioning disorders.

It was demonstrated moreover in the study that the calcium level in uterine fluid was highest at 22 DPP, when its concentration in blood serum was the lowest. According to the authors, this may prove a partial calcium loss to the uterine cavity, which is not subject to further re-absorption. There are other causes of calcium loss in the post partum period in cows apart from via udder, and may at least partially contribute to deficiencies of this element (Kronqvist et al., 2011). This may occur in the post partum period, mainly in situations of enlarged uterus size. It should also be added that in cows without endometritis, higher blood serum calcium levels were noted concurrently with its low levels in uterine fluid at the same post partum period. Moreover, the calcium level in serum of cows with endometritis was lower compared to the control cows for the whole experimental period, and the cows from both groups were at the same lactation stage and so element levels should also have been similar. Therefore, lowered calcium concentrations in blood serum with concurrent elevation of their amounts in the uterus in cows with endometritis may prove the loss of this element only by uterus.

\section{Conclusion}

The obtained results of the study showed that in cows with endometritis uterine involution process is slower than in cows without endometritis. In addition, it was 
also found that the level of calcium in blood serum was lower and levels of calcium, magnesium and protein in the washings of the uterus were higher in cows with endometritis compared to healthy cows. The observed difference in concentration of these elements in particular in the uterine washings may be used not only in the diagnosis of disorders of uterine involution, but also in assessing the activity of the muscle fiber of myometrium.

\section{References}

B el1 M.J., Roberts D.J. (2007). The impact of uterine infection on a dairy cow's performance. Theriogenology, 68: 1074-1079.

B i c a 1 h o R.C., M a cha do V.S., B i c a 1 h o M.L., Gil b e rt R.O., Te i x e ri a A.G.,C a ix e t a L.S., Pereira R.V. (2010). Molecular and epidemiological characterization of bovine intrauterine Escherichia coli. J. Dairy Sci., 93: 5818-5830.

Čengić B., Varatanović N., Mutevelić T., Katica A., Mlačo N., Ćutuk A. (2012). Normal and abnormal uterine involution in cows monitored by ultrasound. Biotechnol. Anim. Husb., 28: 205-217.

Földi J., Kulcsár M., Pécsia A., Huyghe B., De Sa C., Lohuis J.A., Cox P., $\mathrm{Hu}$ s z en i c za G. (2006). Bacterial complications of postpartum uterine involution in catle. Anim. Reprod. Sci., 96: 265-281.

G a lv ã o K.N. (2012). Postpartum uterine diseases in dairy cows. Anim. Reprod., 9: 290-296.

Gautam G., Nako T., Koike K., Long S.T., Yusuf M., Ranasinghe R.M., Hayas h i A. (2010). Spontaneous recovery or persistence of postpartum endometritis and risk factors for its persistence in Holstein cows. Theriogenology, 73: 168-179.

G i l b e r t R.O. (2011). The effects of endometritis on the establishment of pregnancy in cattle. Reprod. Fert. Develop., 24: 252-257.

G o f $f$ J.P. (2008). Immune suppression around the time of calving and the impact of metabolic disease. Hung. Vet. J., 130: 39-41.

H u g e n t o b l e r S.A., M or r is D.G., S re e n a n J.M., D is k in M.G. (2007). Ion concentrations in oviduct and uterine fluid and blood serum during the estrous cycle in the bovine. Theriogenology, 68: $538-548$.

Ka simanickam R., Duffield T.F., Foster R.A., Gartley C.J., Le slie K.E., Walt o n J.S., J o h n s o n W.H. (2004). Endometrial cytology and ultrasonography for the detection of subclinical endometritis in postpartum dairy cows. Theriogenology, 62: 9-23.

Kronqvist C., Emanuels on U., S pörndly R., Holtenius K. (2011). Effects of prepartum dietary calcium level on calcium and magnesium metabolism in periparturient dairy cows. J. Dairy Sci., 94: 1365-1373.

Le Blanc S.J., Duffield T.F., Le slie K.E., B ateman K.G., Ke efe G.P., Walton J.S., Johns on W.H. (2002). Defining and diagnosing postpartum clinical endometritis and its impact on reproductive performance in dairy cows. J. Dairy Sci., 85: 2223-2236.

L e u r e n t C., S u th ar V., H e u w i e s e r W. (2013). Evaluation of transrectal examination of cervical diameter by palpation in dairy cows. J. Dairy Sci., 96: 1063-1070.

M a r s hal1 J.M. (1962). Regulation of activity in uterine smooth muscle. Physiol. Rev., 42: 213-227.

Parkington H.C., Cole man H.A. (2001). Excitability in uterine smooth muscle. Front. Horm. Res., 27: 179-200.

Potter T.J., Guitian J., Fishwick J., Gordon P.J., Sheldon I.M. (2010). Risk factors for clinical endometritis in postpartum dairy cattle. Theriogenology, 74: 127-134.

Sabounchi-Schutt F., Astrom J., Hellman U., Eklund A., Grunwald J. (2003). Changes in bronchoalveolar lavage fluid proteins in sarcoidosis: a proteomics approach. Eur. Respir. J., 21: 414-420.

Sheldon I.M., Lew is G.S., Le Blan c S., Gilbert R.O. (2006). Defining postpartum uterine disease in cattle. Theriogenology, 65: 1516-1530. 
She ld on I.M., Willi a m s E.J., M ille r A.N., N a s h D.M., H e r a th S. (2008). Uterine diseases in cattle after parturition. Vet. J., 176: 115-121.

Sheldon I.M., Cronin J., Goetze L., Donofrio G., Schuberth H.J. (2009 a). Defining postpartum uterine disease and the mechanisms of infection and immunity in the female reproductive tract in cattle. Biol. Reprod., 81: 1025-1032.

Sheldon I.M., Price S.B., Cron in J., Gilbert R.O., Gads by J.E. (2009 b). Mechanisms of infertility associated with clinical and subclinical endometritis in high producing dairy cattle. Reprod. Domest. Anim., 44: 1-9.

Singh J., Murray R.D., Mshelia G., Woldehiwet Z. (2008). The immune status of the bovine uterus during the peripartum period. Vet. J., 175: 301-309.

W a th e s D.C. (2012). Mechanisms linking metabolic status and disease with reproductive outcome in the dairy cow. Reprod. Dom. Anim., 47: 304-312.

Watti e z R., F a l mag ne P. (2005). Proteomics of bronchoalveolar lavage fluid. J. Chromatogr. B Analyt. Technol. Biomed Life Sci., 815: 169-178.

Received: 9 VII 2015

Accepted: 18 I 2016 